\title{
Calcium: More Than Bone? Implications for Clinical Practice and Theory
}

\author{
Jacob M. Hands ${ }^{\mathrm{a}, \mathrm{b}}$, Lawrence S. Moy
}

\begin{abstract}
Serum calcium is routinely screened, but rarely scrutinized in the context of normal, physiologic functioning. This brief review strives to explore the implications of serum calcium, suggests guidelines for its interpretation, and discusses the implications of high, low, and "normocalcemia" in the clinical setting. We find that serum $\mathrm{Ca}^{2+}$ concentrations are a valuable prognostic indicator in routine metabolic workups and advocate for greater attention, on behalf of the provider, to variations in a patient's calcemic status. Variations in calcemic status are primarily tied to malignancy, impaired parathyroid hormone (PTH) secretion, defects in vitamin D synthesis, insulin-like growth factor 1 (IGF-1) fluctuation, genetic syndromes (DiGeorge syndrome) and calcium-sensing receptor $(\mathrm{CaSR})$ mutation. Prognostic implications for high and low serum $\mathrm{Ca}^{2+}$ include, but are not limited to, increased thromboembolic and major adverse cardiovascular event (MACE) risk, cardiac remodeling, hypertension, cognitive decline, and insulin resistance.
\end{abstract}

Keywords: Calcium; Osteoporosis; Bone mineral density; Phosphorous; IGF-1; Vitamin D; Calcitriol

\section{Introduction}

Calcium's role in the clinical setting is seldom disputed, but rarely elucidated. Traditional explanations tend to invoke defects in signaling cascades, $\mathrm{pH}$ alteration (with regard to relevant changes in anion gap), and bone mineral density (BMD). Yet, calcium's role is paramount, if not integral to the near totality of biophysiological pathways in the human body. Accordingly, this review strives to provide a more practical outline for the interpretation of serum calcium and discuss its implications for the clinical setting.

Manuscript submitted April 20, 2021, accepted May 8, 2021

Published online May 25, 2021

aSouth Bay Institute of Clinical Research, University of California, Berkeley, CA, USA

${ }^{b}$ Corresponding Author: Jacob M. Hands, South Bay Institute of Clinical Research, University of California, Berkeley, CA,

USA. Email: jakehands@berkeley.edu

doi: https://doi.org/10.14740/jocmr4505

\section{Evolution and Mechanics}

Calcium's role in the function of biological systems appeared alongside the genesis of planetary life [1]. As seas were deluged with various minerals $(\mathrm{Mg}, \mathrm{Zn}, \mathrm{Ca}, \mathrm{Na}, \mathrm{Pi})$, inchoate cellular life had to navigate limitations on growth and longevity, such as precipitation and osmotic pressure that arose in the course of extracellular feeding. Calcium, in particular, was likely present in excess [2] and bore properties, which rendered it uniquely lethal to the earliest forms of cellular life, namely due to its potential for precipitation in the presence of phosphorus and its consequent role in cytosolic solubility and maintenance of membrane potential $[1,3]$. More intriguing was the hydration variability ( $6-8$ water molecules) of ionized calcium $\left(\mathrm{Ca}^{2+}\right)$; the sheer rapidity of this exchange distinguishes calcium as the fastest divalent binding agent [1], outcompeting $\mathrm{Mg}^{2+}$. Equally germane to calcium's predominance is its maximal affinity for carboxylate oxygen, a major motif present in amino acid containing acidic residues including aspartic acid and glutamic acid [2]. The above properties favored calcium's supremacy in proto-biochemical physiology.

As organisms evolved, calcium was harnessed as a powerful secondary messenger. More specifically, it is thought that calcium is an ancestor of long-range signaling molecules (e.g., hormones) $[1,3]$. Concentrations of intracellular $\mathrm{Ca}^{2+}$ were tightly regulated, its influx and efflux tied to signaling cascades facilitating membrane entry, exit, motility, apoptosis among other functions. As organisms evolved, calcium's primacy was retained. Protein adaptors, such as calmodulin, gradually developed, thereby enabling $\mathrm{Ca}^{2+}$ to interact on the scale of proteins and execute increasingly elaborate tasks [3]. In the course of billions of years of evolutionary pressure, humans remain calcium dependent. Its role no longer confined to signaling but present in a near multiplicity of functions across body systems.

\section{Abundance and Regulatory Function}

Of all calcium in the human body, $99 \%$ is stored as bone in the form of hydroxyapatite. The remaining about $1 \%$ present is either ionized $(51 \%)$, protein bound $(40 \%)$, or chelated $(9 \%)$ [4]. What is denoted as serum calcium is actually "free" or "ionized" $\mathrm{Ca}^{2+}$. Ionized calcium is responsible for regulating various physiologic functions, including intracellular and extracellular $\mathrm{Ca}^{2+}$ concentrations [4]. Free $\mathrm{Ca}^{2+}$ readily complex- 


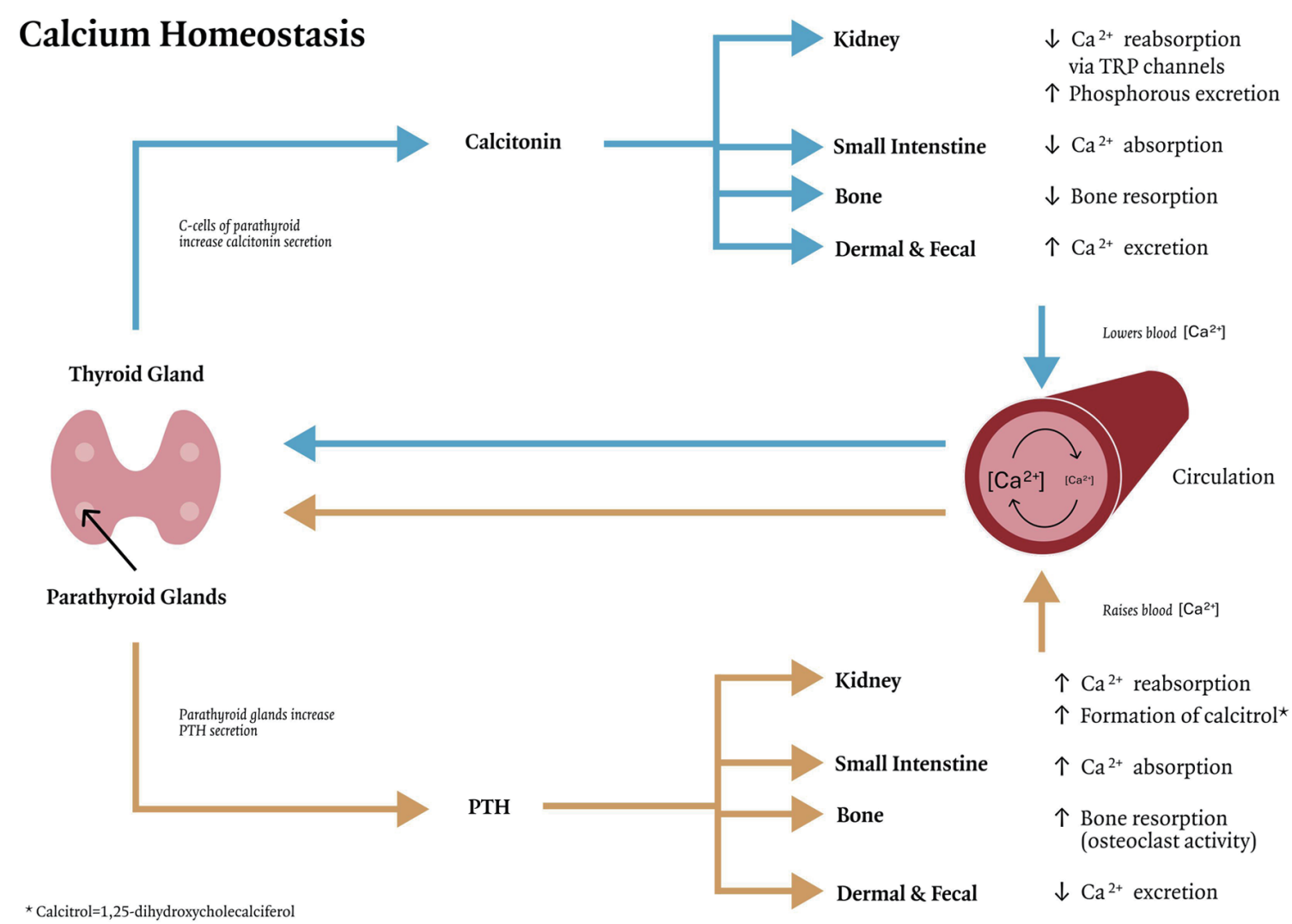

Figure 1. Physiologic mechanisms of calcium homeostasis. Calcium is raised via the release of parathyroid hormone (PTH). PTH secretion increases $\mathrm{Ca}^{2+}$ absorption in the kidneys and small intestine and decreases excretion through dermal and fecal routes. PTH enhances the formation of calcitriol in the kidneys in concert with insulin-like growth factor 1 . Bone resorption is increased. Calcium is lowered via calcitonin secretion from $\mathrm{C}$ cells of the parathyroid. Calcitonin downregulates $\mathrm{Ca}^{2+}$ absorption in the kidneys and small intestine, and increases dermal and fecal excretion of $\mathrm{Ca}^{2+}$. Bone resorption is decreased. TRP: transient receptor potential.

es to form chelated compounds such as calcium phosphate, calcium carbonate and calcium oxalate. Protein-bound calcium is largely present as albumin, to a lesser extent as lactate and citrate $[4,5]$. Ionized $\mathrm{Ca}^{2+}$ is regulated by calcium-sensing receptors (CaSRs), a G-protein coupled receptor (GPCR) primarily staffed in the parathyroid and kidneys. Though, intriguingly, CaSR sites can be found throughout the body including the brain, intestines, bone marrow, pancreas, and eyes. Such a finding lends credence to an understanding of extracellular calcium as central to parenchymal function across the body [6-8]. Intriguingly, genetic defects in the CaSRs are implicated in a range of calcemic disorders and may be investigated upon presentation with hypo- or hypercalcemia after the diagnosis of secondary malignancy, primary parathyroid dysfunction, or vitamin D deficiency has been ruled out $[7,8]$.

Endogenous regulation of serum calcium is chiefly determined by resident CaSRs of the parathyroid and 1, 25-dihydroxyvitamin D. Parathyroid hormone (PTH) is synthesized by the parathyroid in response to decreases in free $\mathrm{Ca}^{2+}$. In response to PTH secretion, vitamin D is converted in the kidneys into its active form $(1,25$-dihydroxyvitamin $\mathrm{D}$ or calcitriol), facilitating decreased urinary excretion of $\mathrm{Ca}^{2+}$ while enhancing excretion of phosphorus. Mechanically, absorption appears mediated by Transient Receptor Potential Channels (TRPs) both canonical (e.g. TRPC6) and non-canonical (e.g. TRPV5/6) in the proximal tubules, ascending loop of Henle, and distal convoluted tubule, affecting coagulation, platelet activity and leukocyte migration [9-11]. Concomitantly, elevations in calcitriol signal increased bone resorption through recruitment of osteoclast activity and enhanced uptake of nutritionally derived calcium in the ileum and jejunum, respectively [12-14]. As free $\mathrm{Ca}^{2+}$ concentrations increase, a negative feedback loop is initiated whereby calcitonin is secreted by parafollicular $\mathrm{C}$ cells in the thyroid, decreasing bone resorption, urinary excretion of phosphorus and nutritionally derived uptake of $\mathrm{Ca}^{2+}$ in the small intestine [12-14]. The net effect is a decrease in serum $\mathrm{Ca}^{2+}$ (Fig. 1).

Of note, there exists a panoply molecular agents (and mineral-based interactions) that referee the process delineated above. Insulin-like growth factor 1 (IGF-1), for example, is a potent mediator of calcitriol synthesis and osteoblast activity, yet is rarely screened alongside vitamin D though it necessarily contributes to endogenous calcium synthesis (via conversion to calcitriol in the kidneys and influence on resorptive potential), and therefore should be evaluated in the context of conditions characterized by calcemic imbalance such as osteo- 
porosis $[13,14]$. More intriguingly, disturbances in IGF-1 secretion (e.g., acromegaly) may result in calcemic disturbance via increased calcitriol synthesis and enhanced phosphatemia. Other factors include the so-called "calcium-phosphorus economy", which denotes the interactive effects associated with phosphorus consumption on calcium absorption and excretion [15]. Indeed, it has been argued that humans primarily evolved in environments characterized by high dietary intakes of calcium relative to phosphorus, a nutritional pattern disrupted during the agricultural revolution [16]; as such, we should expect modern diets to be deficient with regard to dietary calcium. Evidence supporting dietary calcium shortfalls in the human diet is robust and well-replicated $[14,17,18]$.

\section{Calcium Across Lifespan}

Serum calcium levels are inconstant throughout the human development [16, 10, 19]. Advanced age, pregnancy, and adolescence mark the most substantial deviations from normocalcemia [10]. The latter two coincide with greater serum concentrations of $\mathrm{Ca}^{2+}$, with the former associated with a decrease in $\mathrm{Ca}^{2+}$. Adolescent increases in $\mathrm{Ca}^{2+}$ are transient and appear to be linked to a number of factors including accelerated bone formation, increases in endogenous IGF-1 (therefore, growth hormone $(\mathrm{GH})$ ), and coeval spikes in sex hormones [10]. Estrogen, in particular, plays a prominent role in osteoblast activity, effectively mediating BMD; unsurprisingly, periods of estrogen depletion (e.g., menopause) coincide with substantial decreases in BMD, and are considered partially explanatory in the development of osteoporosis [10]. It may be of relevance that age-related declines in IGF-1 are coincident with waning estrogen during peri- and postmenopausal periods.

Serum calcium concentrations, once a homeostatic level is achieved, are remarkably well maintained in a given, healthy individual and hover between $8.5-10.5 \mathrm{mg} / \mathrm{dL}$, rarely deviating by $>2 \%[10,20]$. Younger subjects report higher serum calcium levels $[14,16,10]$. Calcium's relevance, though ageindependent in most respects, is pronounced in early life and adolescence. Fetal calcium levels are markedly high, with values decreasing with increasing age. BMD is largely explanatory. For example, it is estimated that more than $90 \%$ of bone mass is obtained by age $<20$, with BMD peaking at about 30 [16]. Upregulation of dietary $\mathrm{Ca}^{2+}$ uptake is pronounced in early life, while fecal and dermal excretion appears attenuated $[10,21,22]$. Importantly, dietary calcium intake during critical periods (early childhood and adolescence) significantly impacts midlife BMD for most groups [10, 21-23]. Intriguingly, sex and ethnicity mediate this process with certain groups such as African Americans and males (of all ethnicities) reporting greater BMD, and BMD peaks across cultures [10].

\section{Clinical Implications of Serum $\mathrm{Ca}^{2+}$}

The clinical implications of $\mathrm{Ca}^{2+}$ are varied. Calcium's essential role in transduction and propagation implies that deficiencies in serum $\mathrm{Ca}^{2+}$ be met with altered signaling. As $\mathrm{Ca}^{2+}$ plummets, global transduction is disturbed. Tetany, hyper-excitability, seizure and arrhythmia are common under regimes of severe $\mathrm{Ca}^{2+}$ deficiency [14]. Patients may describe tingling and or numbness; electrocardiographic changes may be observed such as prolonged QT and ST intervals owing to delays in ventricular repolarization [14, 17]. Treatment in these subjects may be emergent and involve immediate restoration of electrolyte imbalance. Inciting factors may include PTH deficiency (PTH disorders (e.g., hypoparathyroidism)), mineral-based triggers (e.g., hypomagnesemia), vitamin D insufficiency (VDI), and certain genetic conditions such as DiGeorge syndrome (22q11.2 deletion). Calcemic disturbance may also arise transiently, as a consequence of transfusion, mineralization, and due to complications arising from a primary malignancy [10-19, 21-24].

The signs of hypercalcemia are often more subtle and tend to appear at two standard deviations above normocalcemia (i.e., $>12 \mathrm{mg} / \mathrm{dL}$ ). Its incidence is reported at about $1 / 1,000$ in the general population and accounts for $<1 \%$ of total hospital admissions [25]. Patients often report nausea/vomiting, musculoskeletal pain, lethargy, confusion, memory impairment, constipation, polyuria, polydipsia, and renal stone formation, commonly abbreviated as "groans, bones, stones, and moans" [25-27]. Electrocardiographic changes may be present including: ST elevation, QRS/PR prolongation, J-waves and Twave inversion/flattening [25]. Primary hyperparathyroidism (PHPT) is implicated in the vast majority of cases followed by malignancy. Eighty-five percent of PHPT cases can be linked to pituitary adenomas and carry an excellent prognosis. Those owing to malignancy, however, are typically associated with poor prognoses and result from parathyroid hormone-related protein production (PTHrP), a peptide chain implicated in cellular growth, differentiation, and osteoclast activity [27]. Soft tissue calcification may result from long-term elevations in serum $\mathrm{Ca}^{2+}$.

\section{Implications for Clinical Theory}

In the clinical setting, identification of calcemic disorders is routine and easily discovered during metabolic screening. The implications, however, of silent, sub-clinical deviations from normocalcemia are without definition and largely unknown. Though, there is evidence to suggest that variation in serum $\mathrm{Ca}^{2+}$ ranges is indeed consequential and has implications for disease susceptibility [28-34].

Present findings suggest there exists a U-shaped curve associated with serum $\mathrm{Ca}^{2+}$ [28]; subjects in the highest tertiles of "normal" serum $\mathrm{Ca}^{2+}(>9.8-9.9 \mathrm{mg} / \mathrm{dL}$ serum-corrected calcium (sCA)) face outsized risk across a range of cardiovascular, endocrine and neurologic diseases including but not limited to: atherosclerosis, left ventricular ejection fraction, cardiac remodeling, ischemic stroke risk, acute myocardial infarction (AMI), hypertension, dementia and insulin resistance [28-32]. Similarly, subjects with low sCA appear to face similar but not identical risks such as renal dysfunction, dementia, impaired stroke and acute myocardial infarction recovery [28, $33,34]$. Though it is difficult to disentangle causality, calcium's 
multifarious role in all parts of the body renders it a candidate for consideration. In the case of stroke and coagulopathies, for example, calcium's participation in fibrinolysis via factor VIII mobilization and platelet activity offer evidence supporting a role for serum $\mathrm{Ca}^{2+}$ in the maintenance of clotting, and may offer insights into thromboembolic risk. More intriguing is the possible role of serum $\mathrm{Ca}^{2+}$ in atherogenesis. Why those in the highest standard deviations of normocalcemia are subject to outsized atherosclerotic risk is a striking observation, and has been attributed to mineralization of the lumen, ultimately solidifying plaques and, thus, leading to vessel narrowing [35].

More broadly, that high or low to normal serum $\mathrm{Ca}^{2+}$ levels are predictive and possibly pathogenic is an important finding that highlights the need for a more careful consideration by the provider, so that they may better dictate care and articulate risk for patients moving forward.

\section{Conclusions}

Calcium is a widely underappreciated component of normal, physiologic functioning. This review strives to refocus provider care and argues that greater attention be paid to serum $\mathrm{Ca}^{2+}$ levels during routine evaluation.

\section{Acknowledgments}

We are grateful to Paul K. Shitabata, M.D. for his expertise and thoughtful contributions.

\section{Financial Disclosure}

None to declare.

\section{Conflict of Interest}

None to declare.

\section{Author Contributions}

JM Hands wrote the piece; LS Moy reviewed and contributed to its conceptual framework.

\section{Data Availability}

The authors declare that data supporting the findings of this study are available within the article.

\section{References}

1. Jaiswal JK. Calcium - how and why? J Biosci. 2001;26(3): 357-363.
2. Williams RJ. The evolution of calcium biochemistry. Biochim Biophys Acta. 2006;1763(11):1139-1146.

3. Clapham DE. Calcium signaling. Cell. 2007;131(6):10471058.

4. Yu E, Sharma S. Physiology, Calcium. [Updated Aug 29, 2020]. In: StatPearls [Internet]. Treasure Island (FL): StatPearls Publishing; Jan 2020. Available from: https:/www. ncbi.nlm.nih.gov/books/NBK482128/.

5. Lian IA, Asberg A. Should total calcium be adjusted for albumin? A retrospective observational study of laboratory data from central Norway. BMJ Open. 2018;8(4):e017703.

6. Hendy GN, Bastepe M, Cole DEC. Parathyroid disorders. Emery and Rimoin's principles and practice of medical genetics. Academic Press. 2013.

7. Thakker RV. Calcium-sensing receptor: Role in health and disease. Indian J Endocrinol Metab. 2012;16(Suppl 2): S213-216.

8. Conigrave AD. The calcium-sensing receptor and the parathyroid: past, present, future. Front Physiol. 2016;7:563.

9. Paez Espinosa EV, Lin OA, Karim ZA, Alshbool FZ, Khasawneh FT. Mouse transient receptor potential channel type 6 selectively regulates agonist-induced platelet function. Biochem Biophys Rep. 2019;20:100685.

10. Weaver CM, Heaney RP. (Eds.) Calcium in Human Health. Nutrition and Health. 2006.

11. Moor MB, Bonny O. Ways of calcium reabsorption in the kidney. Am J Physiol Renal Physiol. 2016;310(11):F1337F1350.

12. Drake TM, Gupta V. Calcium. [Updated Oct 5, 2020]. In: StatPearls [Internet]. Treasure Island (FL): StatPearls Publishing; Jan 2020. Available from: https://www.ncbi. nlm.nih.gov/books/NBK557683/.

13. Yu E, Sharma S. Physiology, calcium. [Updated Aug 29, 2020]. In: StatPearls [Internet]. Treasure Island (FL): StatPearls Publishing; Jan 2020. Available from: https:// www.ncbi.nlm.nih.gov/books/NBK482128/.

14. Goldstein DA. Serum calcium. In: Walker HK, Hall WD, Hurst JW, editors. Clinical methods: the history, physical, and laboratory examinations. 3rd edition. Boston: Butterworths; 1990. Chapter 143. Available from: https://www. ncbi.nlm.nih.gov/books/NBK250/.

15. Heaney RP. Phosphorus nutrition and the treatment of osteoporosis. Mayo Clin Proc. 2004;79(1):91-97.

16. Power ML, Heaney RP, Kalkwarf HJ, Pitkin RM, Repke JT, Tsang RC, Schulkin J. The role of calcium in health and disease. Am J Obstet Gynecol. 1999;181(6):15601569.

17. Cormick G, Belizan JM. Calcium intake and health. Nutrients. 2019;11(7):1606. Published Jul 15, 2019.

18. Beto JA. The role of calcium in human aging. Clin Nutr Res. 2015;4(1):1-8.

19. Roizen JD, Shah V, Levine MA, Carlow DC. Determination of reference intervals for serum total calcium in the vitamin D-replete pediatric population. J Clin Endocrinol Metab. 2013;98(12):E1946-1950.

20. Institute of Medicine (US) Committee to Review Dietary Reference Intakes for Vitamin D and Calcium. Ross AC, Taylor CL, Yaktine AL, et al., editors. Dietary Reference Intakes for Calcium and Vitamin D. Washington (DC): 
National Academies Press (US); 2011. 2, Overview of Calcium. Available from: https://www.ncbi.nlm.nih.gov/ books/NBK56060/.

21. Kalkwarf HJ, Khoury JC, Lanphear BP. Milk intake during childhood and adolescence, adult bone density, and osteoporotic fractures in US women. Am J Clin Nutr. 2003;77(1):257-265.

22. Matheson EM, Mainous AG, 3rd, Carnemolla MA. The association between onion consumption and bone density in perimenopausal and postmenopausal non-Hispanic white women 50 years and older. Menopause. 2009;16(4):756759.

23. Opotowsky AR, Bilezikian JP. Racial differences in the effect of early milk consumption on peak and postmenopausal bone mineral density. J Bone Miner Res. 2003;18(11):1978-1988.

24. Parfitt AM, Kleerekoper M. Clinical disorders of calcium, phosphorus and magnesium metabolism. In: Maxwell MH, Kleeman CR, eds. Clinical disorders of fluid and electrolyte metabolism. New York: McGraw-Hill, 1980:947-1153.

25. Sadiq NM, Naganathan S, Badireddy M. Hypercalcemia. [Updated 2020 Sep 10]. In: StatPearls [Internet]. Treasure Island (FL): StatPearls Publishing; Jan, 2020. Available from: https://www.ncbi.nlm.nih.gov/books/NBK430714/.

26. Turner JJO. Hypercalcaemia - presentation and management. Clin Med (Lond). 2017;17(3):270-273.

27. Goltzman D. Approach to hypercalcemia. [Updated 2019 Oct 29]. In: Feingold KR, Anawalt B, Boyce A, et al., editors. Endotext [Internet]. South Dartmouth (MA): MDText.com, Inc.; 2000. Available from: https://www.ncbi. nlm.nih.gov/books/NBK279129/.

28. Shiyovich A, Plakht Y, Gilutz H. Serum calcium levels independently predict in-hospital mortality in patients with acute myocardial infarction. Nutr Metab Cardiovasc Dis. 2018;28(5):510-516.

29. Sato H, Nagasawa T, Saito A, Miyazaki M. Risk of cardiovascular mortality predicted by the serum calcium level and calcification score at the initiation of dialysis. Clin Exp Nephrol. 2018;22(4):957-966.

30. Wu X, Han T, Gao J, Zhang Y, Zhao S, Sun R, Sun C, et al. Association of serum calcium and insulin resistance with hypertension risk: a prospective population-based study. J Am Heart Assoc. 2019;8(1):e009585.

31. Poudel K, Shah AM, Michos ED, Folsom AR, Konety S, Lutsey PL. Association of serum calcium and phosphorus with measures of left ventricular structure and function: The ARIC study. Nutr Metab Cardiovasc Dis. 2020;30(5):758-767.

32. Miller JE, Kovesdy CP, Norris KC, Mehrotra R, Nissenson AR, Kopple JD, Kalantar-Zadeh K. Association of cumulatively low or high serum calcium levels with mortality in long-term hemodialysis patients. Am J Nephrol. 2010;32(5):403-413.

33. Ovbiagele B, Starkman S, Teal P, Lyden P, Kaste M, Davis SM, Hacke W, et al. Serum calcium as prognosticator in ischemic stroke. Stroke. 2008;39(8):2231-2236.

34. Sato K, Mano T, Ihara R, Suzuki K, Tomita N, Arai H, Ishii $\mathrm{K}$, et al. Lower serum calcium as a potentially associated factor for conversion of mild cognitive impairment to early Alzheimer's disease in the Japanese Alzheimer's disease neuroimaging initiative. J Alzheimers Dis. 2019;68(2):777-788.

35. Kalampogias A, Siasos G, Oikonomou E, Tsalamandris $\mathrm{S}$, Mourouzis K, Tsigkou V, Vavuranakis M, et al. Basic mechanisms in atherosclerosis: the role of calcium. Med Chem. 2016;12(2):103-113. 